Journal of Universal Language 6

September 2005, 117-153

\title{
Desideratives and Person: Constructing a Semantic Map*
}

\author{
Toshihiro Sugawara
}

University of Manitoba

\begin{abstract}
This paper examines the implications of grammatical person for desiderative constructions from a cross-linguistic perspective. It is widely known that some grammatical systems in a language, such as pronoun systems, number distinction, and case marking systems, are sensitive to person differences. In this study, in addition to such grammatical systems, it was found that grammatical person also affects the form of desiderative constructions in several languages. In languages such as Japanese, Korean, Hua, and Cocopa, the form of desiderative construction with third person subject is somewhat differently constructed from that with first/second person subject. Also, in Samoan, the first and second person singular clitics are treated differently from the other person/ number clitics in desiderative constructions. In addition, it was found in Tagalog that the third person pronoun shows a different pattern regarding the use
\end{abstract}

\footnotetext{
* I would like to thank Terry Janzen for his invaluable comments, advice, and suggestions throughout this study. I would also like to thank Christoph Wolfart and Lorna MacDonald for their invaluable comments.
} 
118 Desideratives and Person: Constructing a Semantic Map

of enclitic sana from lexical nouns and other person pronouns. In order to capture the phenomena found in these languages, then, a semantic map model is adopted in this study, and a conceptual space is proposed for desideratives within which the distinctions found in this study are represented.

Keywords: desiderative, person, animacy hierarchy, semantic map, conceptual space

\section{Introduction}

It has been pointed out in the literature that some grammatical systems and constructions in a language, such as pronoun systems, number distinction, verbal agreement and case marking, are sensitive to person differences (e.g., Silverstein 1976, Dixon 1979, Comrie 1989). However, in certain languages, in addition to such grammatical systems or constructions, desiderative constructions are also sensitive to differences of grammatical person (and number). ${ }^{1}$ In other words, there is a split in the form of the desiderative construction in terms of grammatical person. In this paper, then, I discuss how the split is manifested in these languages, and propose an underlying conceptual space for desiderative constructions by which the patterns of splits found in desiderative constructions are captured, by adopting a semantic map model (e.g., Croft 2003). The languages that show a person split in desiderative constructions in this study are Cocopa (Hokan), Hua (Trans-New Guinea), Japanese (Japanese), Korean (Language Isolate), Samoan (Central Malayo-Polynesian), Kurmanji (Indo-Iranian), and Tagalog (Western

\footnotetext{
1 In this study, the term, desiderative, is understood as a semantic category referring to any expression by which one's desire is expressed, following Noonan (1985), thereby expressions that convey the meanings of such as 'want', 'hope', and 'wish' are treated in the same way as desideratives.
} 
Malayo-Polynesian). The discussion in this paper is based on desiderative constructions in those languages. The structure of this paper is as follows. The following section discusses the semantic map model that is adopted in this paper. Section three then examines cases in which the form of desiderative constructions differs somewhat between first/second person subject and third person subject. Section four looks at cases in which a split is found between first/second person singular and other person/number combinations. Section five is concerned with a case in which third person pronouns are treated somewhat differently from other person categories. To integrate the discussions in the previous sections, section six proposes a conceptual space (or underlying diagram based on each distinction) for desideratives by adopting the semantic map model, and illustrate how the distinctions found in this study are represented in the model. Section seven offers an overall conclusion.

\section{Semantic Map Model}

A semantic map model has been developed by such as Anderson (1982), Kemmer (1993), Haspelmath (1997, 2003), and Croft (2001, 2003), so as to provide "a representation of both language universals and language-specific grammatical knowledge" (Croft 2003: 133). The semantic map model gives us significant benefits to approaching language universals in that it makes cross-linguistic comparison possible, helps us to reveal universal semantic (or functional) structure, and leads us to find implicational universals as a side effect (Haspelmath 2003: 230).

In the semantic map model, there are two kinds of diagrams: "conceptual space" and "semantic map" (Croft 2001, 2003). However, they are not separate, discrete diagrams from one another: "conceptual space is the underlying conceptual structure, and a 
semantic map is a map of language-specific categories on the conceptual space" (Croft 2001: 94). The former, conceptual space, concerns itself with language universals, defined as "a structured representation of functional structures and their relationship to each other" (Croft 2001: 93).

In a conceptual space, each function (or category) is represented "linked by connecting lines and thus constitute a network" (Haspelmath 2003: 213). In the model, this network of functions is considered to be the universal across languages: "what is the universal across languages is the structure of the underlying diagram itself: the values and the links between the values" (Croft 2003: 133-4).

To construct a conceptual space, first, a category (or function) is selected and placed in a diagram "if there is at least one pair of language that differ with respect to this function" (Haspelmath 2003: 217). After categories or functions that have to do with the grammatical phenomenon are selected, they are arranged in the diagram to "occupy a contiguous area" (ibid.: 217), according to the semantic map connectivity hypothesis: "any relevant languagespecific and construction-specific category should map onto a connected region in conceptual space" (Croft 2001: 96). The following is an example of a conceptual space of the dative provided by Haspelmath (2003).

(1) Conceptual Space for the Dative

(Adapted from Haspelmath 2003: 213)

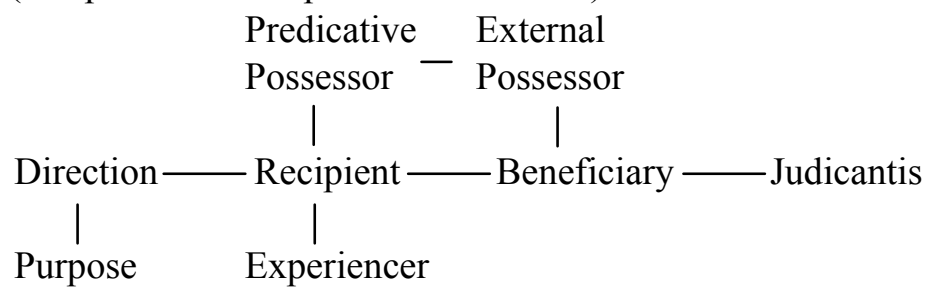


A semantic map is then drawn on the underlying conceptual space, according to the distributions or patterns found in a specific form or construction in a language. For English to, for instance, since it is used as a marker of direction, recipient, experiencer and purpose, but not of predicative possessor, external possessor, beneficiary, or judicantis as in (2), its multifunctionality is represented by an enclosed region as a semantic map as in (3).

(2) Functions of English to (Haspelmath 2003: 212-213)

a. Direction: Goethe went to Leipzig as a student.

b. Recipient: Eve gave the apple to Adam.

c. Experiencer: This seems outrageous to me.

d. Purpose: I left the party early to get home in time.

e. Predicative possossor: *This dog is to me.

f. Beneficiary: I'll buy a bike for/*to you.

g. Judicantis (Judger's Dative): That is too warm for/*to me.

(3) Semantic Map for English to

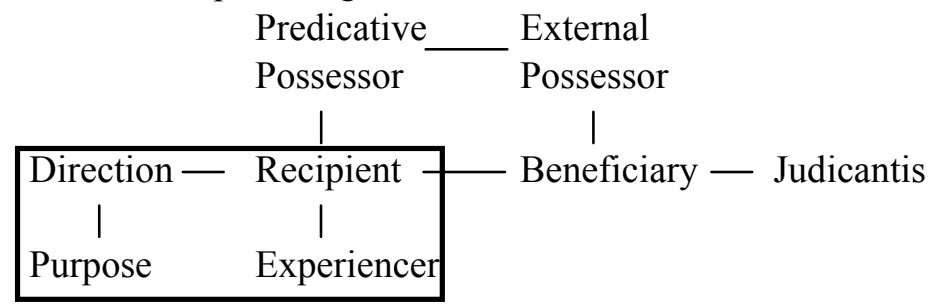

(English to)

In the same underlying conceptual space, functions of dative markers in other languages can be represented for comparison. For example, functions of French $\grave{a}$ and dative clitics are represented (with the functions of English to) as in (4). ${ }^{2}$

${ }^{2}$ For the sake of simplicity of discussion, examples for French $\grave{a}$ and dative clitics are omitted. 
122 Desideratives and Person: Constructing a Semantic Map

(4) Semantic Map for English to and French à and Dative Clitics

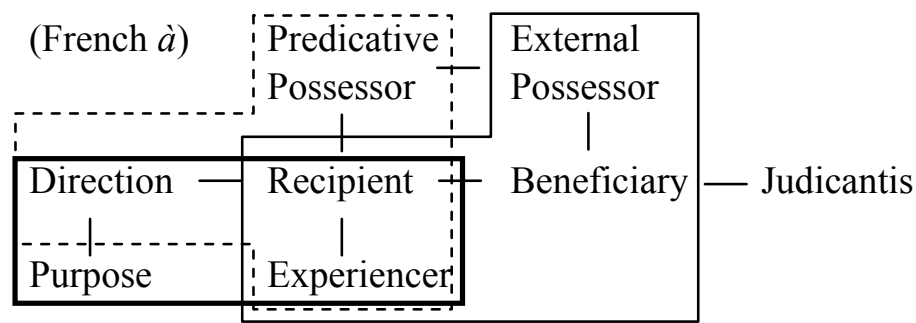

(English to)

(French Dative Clitics)

That is, as the representation above suggests, a conceptual space can provide the basis for cross-linguistic comparison of a coding phenomenon. More importantly, however, it can tell us about language universals since "[t]he structure of the conceptual space, represented by the links, constrains possible language types to exclude languages with grammatical categories of distinctions that are not connected in the conceptual space" (Croft 2003: 139). Also, it is important that the semantic map model is beneficial in that it can capture cross-linguistic variation and generalizations without positing universal grammatical categories (ibid.: 138), that are often highly controversial.

\section{1st/2nd vs. 3rd Person}

There are certain languages in which the paradigm of the form of the desiderative construction splits between first/second person and third person. The languages that show such a split are Japanese, Korean, Hua, and Cocopa. In this section those languages are discussed in turn. 


\subsection{Japanese}

In Japanese, one's desire is most frequently expressed by adding the adjectival desiderative suffix -tai to a verbal stem, as in (5). ${ }^{3}$
(5) Watasi-wa susi-o
tabe-tai.
1SG-TOP sushi-ACC eat-DESID
'I want to eat sushi.'

In (5), the verbal stem is tabe 'eat' and the desiderative suffix -tai follows it and constitutes the predicate of the sentence.

However, as Iwasaki (2002: 278) states, "this form is only available for the first person subject in a statement and for the second person subject in a question. It must be modified with the suffix -garu for the third person subject" (-garu can be glossed as 'show a sign of'). Note that when -garu follows the desiderative suffix -tai, the complex form is usually further followed by -teiru 'CONT/ STATE' (Martin 1975: 358, Aoki 1986: 225). Examples in which first/second person is the subject are in (6), and examples in which third person is the subject is in (7).

3 The following abbreviations are used in this paper:

$1=$ first person, $2=$ second person, $3=$ third person, $\mathrm{ACC}=$ accusative, $\mathrm{ART}=$ article, ASSERT $=$ assertive, $\mathrm{CONT}=$ continuous, $\mathrm{COP}=$ copula, $\mathrm{DEC}=$ declarative, $\mathrm{DESID}=$ desiderative, $\mathrm{DL}=$ dual, e=exclusive, $\mathrm{FUT}=$ future, $\mathrm{GEN}=$ genitive, $\mathrm{i}=$ inclusive, $\mathrm{IND}=$ indicative, $\mathrm{INDEF}=$ indefinite, $\mathrm{INF}=$ infinitive, $\mathrm{IRREAL}=$ irrealis, $\mathrm{M}=$ masculine, $\mathrm{NOM}=$ nominative, $\mathrm{NOMLZ}=$ nominalizer, $\mathrm{OBL}=$ oblique, $\mathrm{PERF}=$ perfective, $\mathrm{PL}=$ plural, $\mathrm{POL}=$ polite, $\mathrm{PRED}=$ predicate, $\mathrm{PROG}=$ progressive, $\mathrm{PST}=$ past, $\mathrm{PURP}=$ purposive, $\mathrm{Q}=$ question marker, $\mathrm{REL}=$ relative marker, $\mathrm{SG}=$ singular, STATE=stative, $\mathrm{SUBJN}=$ subjunctive, $\mathrm{TOP}=$ topic, UNS=unspecified tense-aspectmood. 
124 Desideratives and Person: Constructing a Semantic Map

(6) 1st and 2nd Person Subject
a. Watasi-wa ne-tai.
1SG-TOP sleep-DESID
'I want to sleep.'
b. Anata-wa nani-o
'What do you want to eat?' tabe-tai? 2SG-TOP what-ACC eat-DESID
c. * Watasi-wa ne-ta-gat-teiru.
1SG-TOP sleep-DESID-show.a.sign.of-CONT/STATE 'I want to sleep.'
d. * Anata-wa nani-o
2SG-TOP what-ACC
tabe-ta-gat-teiru?
eat-DESID-show.a.sign.of-CONT/STATE
'What do you want to eat?'

(7) 3rd Person Subject
a. Kare-wa
mizu-o
3SG:M-TOP
water-ACC
nom-ita-gat-teiru.
drink-DESID-show.a.sign.of-CONT/STATE
'He wants to drink water.'
b. * Kare-wa
mizu-o
3SG:M-TOP water-ACC
nom-itai.
'He wants to drink water.'
(Aoki 1986: 225)
drink-DESID
(Aoki 1986: 225)

As examples in (6) indicates, when the subject of 'want' is the first/second person, it takes only the desiderative suffix -tai after a verb stem, as in (6a) and (6b), but it does not further require the additional suffix -garu after the desiderative suffix, as in (6c) and (6d), which are shown to be unacceptable. On the other hand, the additional suffix must occur in desiderative constructions when the subject is the third person, as (7a) and (7b) show. 
For the distinction between first/second person and third person in terms of desiderative constructions, Kuno (1973: 83-4) explains that this is because a speaker cannot know other people's internal feelings of desire:

The speaker has no basis for making an affirmative judgment on the second or third person's internal feeling. He can express only his own internal feeling. Hence, only the first person subject is allowed... in affirmative sentences. The speaker can ask about the internal feeling of the hearer, but not about the internal feeling of some third person.

Therefore, it is necessary to make use of some other means when a speaker expresses the third person's desire in a simple statement. The suffix, -garu 'show a sign of', is one of such means in Japanese. Since the suffix -garu functions to "convert inner sensations and desires into a verb which expresses extremely observable changes... (and express) inference rather than direct experience" (Aoki 1986: 225), it becomes possible for a speaker to express a third person's desire.

In fact, there is another means to express a third person's desire other than adding the additional suffix -garu to the desiderative marker -tai. A third person's desire is also expressed as direct quotation or with an expression of sooda 'hearsay' or yooda 'seem'. Again, these means are used only for third person desideratives, but not for first/second person desideratives. Examples for each type are as follows.

(8) 3rd Person Desideratives

a. With Direct Quote

$\begin{array}{llll}\text { Sono } & \text { hito-wa } & \text { doitugo-o } & \text { benkyoo } \\ \text { that } & \text { person-TOP } & \text { German-ACC } & \text { study } \\ \text { si-tai } & \text { to } & \text { itteiru. } & \end{array}$


126 Desideratives and Person: Constructing a Semantic Map

do-DESID that

say:CONT/STATE

'That person says that s/he wants to study German.'

b. With 'hearsay'

Ken-wa Nihon-ni kaer-itai sooda.

K.-TOP Japan-to return-DESID HEARSAY

'I hear that Ken wants to go back to Japan.'

c. With 'seem'
Ken-wa Nihon-ni kaer-itai yooda.
K. -TOP Japan-to return-DESID seem
'Ken seems to want to go back to Japan.'

The expressions, sooda 'hearsay' and yooda 'seem', are expressions by which the proposition expressed with them is understood as the speaker's assertion, based on some available evidence. That is, they are not an expression of a current internal feeling of the third person, but an expression as to how the third person's desire is observed or inferred by the speaker.

Interestingly, a third person's desire is possibly expressed without the additional suffix -garu (or other elements) when it is in the past tense as in (9a).

(9)
a. Ken-wa mizu-o nom-itakatta.
Ken-TOP water-ACC drink-DESID:PST
'Ken wanted to drink water.'
b. * Ken-wa mizu-o nom-itai.
Ken-TOP water-ACC drink-DESID
'Ken wants to drink water.'

However, this is probably limited to written language. Nihongokyoikugakkai (1982: 376) states that a third person's past desire can be expressed without - garu or any other elements, but this kind of expression is likely to be found in literary writings in which the story can be described from the viewpoint of the person in the 
story. That is, in literary writings, although the subject is third person, the person can function as first person in the story, through whose eyes things are described.

All in all, in Japanese, a speaker cannot express other people's desire with a simple statement like He wants to buy a car in English. When a speaker expresses a third person's desire, the expression has to be with a direct quote or some other expression that indicates that the person's desire is heard, observed, or inferred. That is, a third person's desire cannot be expressed in the same way by which a first/second person's desire is expressed. While a first/second person's desire is simply expressed by adding the desiderative suffix -tai to a verb stem, a third person's desire has to be expressed as direct quote, hearsay or inference of the speaker in Japanese.

\subsection{Korean}

The same kind of distinction as in Japanese is found in Korean as well. In Korean, one's desire is usually expressed with the complex form -ko+siph 'NOMLZ+desirous' that follows a verb stem:
(10) Na-nun mikwuk-ey ka-ko siph-ta. 1SG-TOP America-to go-NOMLZ desirous-DEC 'I want to go to America.'

When the subject of 'want' is the first or second person, this desiderative complex is used to express the person's desire as the example above. However, when the subject is the third person, the complex is necessarily further followed by $h a$ 'do', forming a phrase siph-e ha 'desirous-INF+do' in order to be grammatical (Im et al. 1989: 198-9, Martin 1992: 777). This contrast is exemplified as follows. 
(11) Desideratives in Korean (1st and 2nd Person)
a. Na-n
kohyang-ey ka-ko
siph-eyo.
1SG-TOP hometown-to go-NOMLZ desirous-POL
'I wanted to go back to my hometown.' (SPC: $\operatorname{siph} 75)^{4}$
b. $\mathrm{Ne}$,
na-lang kyelhonha-ko
siph-ni?
2SG 1SG-with
marry-NOMLZ
desirous-Q
'You, do you want to marry me?'
(SPC: $\operatorname{siph} 85$ )

(12) Desideratives in Korean (3rd Person)

... tongsayng-un enceyna taycang-i toy-ko

brother-TOP always boss-NOM become-NOMLZ

siph-e ha-pnita.

desirous-INF do-POL

'My brother always wants to become a boss.'

(SPC: siph 234)

In (11), desiderative constructions with first and second person subjects do not require the additional constituent $h a$ 'do' after the desiderative adjective siph 'desirous', while desiderative constructions with a third person subject require it as in (12). This pattern seems to be parallel to the case of Japanese. In Japanese, it is the third person desideratives that require the additional suffix -garu following the desiderative suffix -tai, while the first/second person desideratives do not require it. There is a difference between $h a$ in Korean and -garu in Japanese in meaning in that -garu itself has the meaning of 'show a sign of' which implies that the expressed desire is an observation of the speaker rather than an internal feeling of the third person, while $h a$ in Korean does not convey such a meaning as the gloss indicates (i.e., 'do'). However, the function of the form $h a$ 'do'

\footnotetext{
4 'SPC' stands for the name of the corpus, the 21st century Sejong Project Corpus, and 'siph 75' stands for the 75th return of siph 'desirous' from the concordancer CETConc provided by Korea University.
} 
in Korean is parallel to -garu in Japanese in that it also turns the nature of the desiderative predicate from adjectival to verbal. As the gloss indicates, the additional element $h a$ in Korean is 'do' and becomes the head of the predicate, and therefore the complex predicate as a whole turns out to be verbal. In this regard, the additional verbal element in Korean may also function to "convert inner sensations and desires into a verb which expresses extremely observable changes" (Aoki 1986: 125).

As in Japanese, in Korean a third person's desire can also be expressed with a direct quote or an expression such as -un moyang-ida (REL+appearance-COP) 'seem':

(13) a. With a Direct Quote

$\begin{array}{llcc}\text { Wenhyenim } & \text { ssi-nun... } & \text { halwu ppalli } \\ \text { Wenhyenim } & \text { Mrs.-TOP } & \text { a.day soon } \\ \text { khweyithu-lo } & \text { tolaka } & \text { namphyen-ul } \\ \text { Kuwait-to } & \text { return } & \text { husband-ACC } \\ \text { manna-ko } & \text { siph-ta-ko } & \text { malha-yssta. } \\ \text { see-NOMLZ } & \text { desirous-DEC-that say-PST }\end{array}$

'Mrs. Wenhyenim said that ... she wanted to go back to Kuwait to see her husband as soon as possible.'

(SPC: siph 154)

b. With -un moyang-ida (REL+Appearance-COP) 'seem'

$\begin{array}{lll}\text { Tokil-uy } & \text { celmuni-tul-un } & \text { ilen } \\ \text { Germany-GEN } & \text { youngster-PL-TOP } & \text { like.this } \\ \text { sik-ulo-lato } & \text { cayu-lul } & \text { mankkikha-ko } \\ \text { way-by-even } & \text { freedom-ACC } & \text { enjoy-NOMLZ } \\ \text { siph-un } & \text { moyang-ida. } & \\ \text { desirous-REL } & \text { appearance-COP } & \\ \text { 'It seems that youngsters in Germany want to enjoy } \\ \text { freedom even in this kind of way.' } & \text { (SPC: siph 653) }\end{array}$


(13a) is an example of a direct quote and (13b) is an example of 'seem'. In (13b), the elements, -un 'REL', moyang 'appearance' and -ida 'COP', together convey a meaning similar to the English word 'seem'. This expression indicates that the speaker comes to know the subject's (i.e., youngsters in Germany) desire through her observation of it. That is, in both expressions, the third person's desires are not directly expressed as their own internal feeling in Korean, but are indirectly expressed as a quote of the person's words, or an observation or inference of the speaker.

In sum, the phenomena found in Korean are parallel to those of Japanese. In Korean too, desideratives with the third person subject are not expressed in the same way by which those with the first/second person subject are expressed. A third person's desire is expressed with an additional element, such as $h a$ 'do', following the desiderative form -ko siph, while a first/second person's desire is expressed without such an additional element.

\subsection{Hua}

In Hua, it is also found that desideratives with the third person subject is somewhat differently constructed from those with the first/second person. When the subject of 'want' is the third person, the person's desire is expressed by means of a direct quote, as in (14). On the other hand, when the subject of 'want' is the first or second person, the person's desire is expressed with a non-direct quote, as in (15) and (16).

(14) 3rd Person Desiderative in Hua ${ }^{5}$

$$
\begin{array}{ll}
\text { "Do-gu-e" } & \text { hi-e. } \\
\text { eat-FUT-IND } & \text { say-IND }
\end{array}
$$

\footnotetext{
5 Person of a subject is encoded on a verb stem (and suffixes) by vowel alternations (Haiman 1980).
} 
'He wants to eat.' (Lit. "II will eat," he says.')

(Haiman 1980: 441)

(15) 1st Person Desiderative in Hua
a. De-su-mi(') hu-e. eat-SUBJN-PURP say-IND
'I want to eat.'
b. Vi-su-'mi(') hu-'e. go-SUBJN-PURP:DL 'We two want to go.' say-IND:DL

(Haiman 1980: 441)

(Haiman 1980: 441)

(16) 2nd Person Desiderative in Hua

De-sa-pe?

eat-SUBJN-Q

'Do you want to eat?'

(Haiman 1980: 441)

In (15a), the constituent, de-su-mi(') 'eat-SUBJN-PURP', is a subordinate clause which cannot independently stand by itself as a sentence. In fact, the subjunctive, $-s u$, in Hua is not contrasted with the indicative in the category of mood. ${ }^{6}$ It functions rather as an auxiliary. According to Haiman (1980: 141), it is used for wishes, opposed to another auxiliary $-g u$ that is used for predictions. It should also be noted that there is a further split between first person and second person. When the subject is the first person, following Haiman's terminology, the desiderative construction ('SUBJNPURP+say') is used, as in (15), while when it is the second person, the subjunctive construction is used, as in (16).

This pattern also parallels the one found in Japanese and Korean in which a direct quote is one of the ways to express a third person's

\footnotetext{
${ }^{6}$ Haiman (1980: 141) notes that labeling the suffix $-s u$ as subjunctive is a "misnomer," but I follow his terminology in this paper.
} 
132 Desideratives and Person: Constructing a Semantic Map

desire. $^{7}$ Accordingly, it may also apply to Hua, as to Japanese and Korean, that a speaker cannot express a third person's desire with a simple assertive statement since the speaker cannot directly experience the third person's desire, so that it is expressed with a direct quote.

\subsection{Cocopa}

Cocopa seems to also be a language in which a third person's desire is somewhat differently expressed from that of first/second person's. In Cocopa, the desiderative marker $-L^{y 8}$ is used to form desiderative clauses, following the irrealis suffix $-x$ that obligatorily occurs in desiderative constructions, as in (17). ${ }^{9}$

(17)
a. čuwa-x-L $L^{y}$.
1:stay-IRREAL-DESID
'I want to stay.' (Gorbet 1998: 12)
b. pm-wa:y-x-L $\mathrm{L}^{\mathrm{y}}$ 2i-č 2 i-ș.
2/3-call-IRREAL-DESID 1:say-ASP 1:say-ASSERT
'I want you to call him/her.' 10 (Gorbet 1998: 12)

However, this suffix is used only when the subject of 'want' is first or second person. It is not used when the subject is third person (Gorbet 1998: 11-12). ${ }^{11}$ That is, the cut-off line as to whether the

${ }^{7}$ It is unclear that other means such as 'seem' or 'hearsay' are also used to express a third person's desire. No information is provided in Haiman (1980).

8 The desiderative suffix $-L^{y}$ is phonetically realized as voiceless palatal lateral fricative (Crawford 1989).

${ }^{9}$ Whether there is a matrix verb or not does not affect the presence/absence of the desiderative suffix. In Cocopa, desideratives can occur as a main clause or a complement of the verbs such as $-i$ 'say', but "the variation in question is independent of whether there is a matrix verb" (Gorbet 1998: fn.2).

${ }^{10}$ Since the translation was not provided in the source, I added it.

11 Gorbet does not provide ill-formed examples. 
suffix $-L^{y}$ is used or not in desiderative clauses is drawn between first/second person and third person. The first/second person desideratives are overtly marked with the desiderative suffix, while the third person desideratives do not require the suffix.

Although it is unclear as to how and why this difference has been developed in Cocopa, it is certain that there is difference between first/second person and third person in desiderative constructions also in Cocopa.

\subsection{Summary}

In this section, it was discussed that there are certain languages, Japanese, Korean, Hua, and Cocopa, in which a person split is found between first/second person and third person in desiderative constructions. In Japanese, desiderative constructions with a third person subject contain an extra element in addition to the constituent equivalent to 'want' (or 'DESID'), while those with a first/second person subject do not take such an additional element. Korean shows the same pattern as Japanese. Also, the same type of split is found in Hua in which desiderative constructions with a third person subject are expressed with a direct quote, while those with a first/second person subject are expressed with a non-direct quote. In addition, it is found in Cocopa that desiderative constructions with first/second person subjects are overtly marked with the desiderative suffix $-L^{y}$, while those in which the third person is the subject do not require the suffix.

\section{1st/2nd Singular vs. Others}

As discussed in the previous section, there are some languages in which the form of desiderative construction somewhat differs between 
first/second person and third person. In addition to this, in this study, another type of split is found in desideratives, between first/second person singular and other person/number combinations. In this section, I examine two languages, Samoan and Kurmanji, that show this type of split.

\subsection{Samoan}

In Samoan, although so-called equi-deletion is optional in a large class of verbs, it is not allowed in desiderative constructions when it is controlled by a first or second person singular clitic pronoun and the target is the $\mathrm{S}$ argument (i.e., the only argument of a single argument clause) of a desiderative complement (Chung 1978: 126) 12 :

(18) $1 \mathrm{SG}$ and 2SG Clitic in Intransitive Complements

(Chung 1978: 127)
a. *'ua 'ou mana'o e alu e moe.
PERF 1SG want UNS go UNS sleep
'I want to go to sleep.'
b. 'ua 'ou mana'o 'ou te alu 'ou te moe.
PERF 1SG want 1SG UNS go 1SG UNS sleep
'I want to go to sleep.'
c. * pe 'e te mana'o e alu atu 'i lo'u fale?
Q 2SG UNS want UNS go away to my house
'Do you want to go to my house?'

$\begin{array}{llllll}\text { d. pe } & \text { 'e } & \text { te } & \text { mana'o } & \text { 'e } & \\ \text { Q } & \text { 2SG } & \text { UNS } & \text { want } & \text { 2SG } & \\ \text { te } & \text { alu } & \text { atu } & \text { 'i } & \text { lo'u } & \text { fale ? } \\ \text { UNS go gow to } & \text { my } & \text { house } \\ \text { 'Do you want to go to my house?' } & & \end{array}$

12 The verb alu (plural ō) 'go' also shows the same pattern. 
In (18) in which first and second person singular clitics are the subjects of desiderative complements (as well as the subjects of matrix clauses), (a) and (c), in which equi-deletion is applied, are ungrammatical, while (b) and (d), in which equi-deletion is not applied (i.e., the $\mathrm{S}$ of the complement overtly occurs), are grammatical.

This constraint of equi-deletion is only applicable to cases in which the control is one of the first or second person singular clitics. When the control is some other element, the constraint is not applied, as in (19). In (19a), the control is the first person plural clitic, which allows equi-deletion. In (19b), the control is the third person plural clitic, and equi-deletion is also allowed.

(19) 1PL and 3PL Clitic in Intransitive Complements (Chung 1978: 127)
a. na
mātou
mānana'o
UNS
'a'ai.
PST 1PL
want:PL
eat:PL
'We wanted to eat.'
b. sā lātou mānana'o e $\quad \bar{o}$ 'i le 'āiga. PST 3PL want:PL UNS go:PL to the house 'They wanted to go home.'

However, as mentioned previously, equi-deletion is applied only when the complement is intransitive. The following example, (20), shows that the equi-deletion constraint is not applicable to cases in which desiderative complements are transitive. In the example, the control of equi-deletion is the second person singular clitic which does not allow equi-deletion when the complement is intransitive (see (18c)), but does allow equi-deletion when the verb in the desiderative complement is a transitive verb such as faitau 'read'. 
136 Desideratives and Person: Constructing a Semantic Map

(20) 2SG Clitic in Transitive Complements (Chung 1978: 128) 'e te mana'o e faitau le tusi? 2SG UNS want UNS read the book 'Do you want to read the book?'

In addition, when the first or second singular INDEPENDENT pronoun is the control, equi-deletion can be applied, as in (21).
(21) a. 'ua a'u mana'o e alu a'u e moe. ${ }^{13}$ PERF 1SG want UNS go 1SG UNS sleep 'I want that I should go to sleep.' (Chung 1978: 127) b. 'o 'oe e mana'o e sau taeao. PRED 2SG UNS want UNS come tomorrow 'It is you that want to come tomorrow.'

(Chung 1978: 127)

All in all, equi-deletion is not allowed in a desiderative construction when it is controlled by a first or second person singular clitic pronoun and the target is the $\mathrm{S}$ argument of a desiderative complement, while it is allowed under any other conditions.

Considering all the phenomena above, it is remarkable that the split in Samoan desiderative construction is sensitive to "number hierarchy" (Corbett 2000: 38) as well as person hierarchy. The split observed in Samoan desiderative construction above can be summarized, as in (22).

${ }^{13}$ In her monograph, Chung presented the first person singular independent pronoun as 'ou, but this may have been an error. According to Mosel and Hovdhaugen (1992: 121), the first person singular independent pronoun is $a^{\prime} u$. Therefore, 'ou is replaced with $a^{\prime} u$ in this example. 
(22) Split of Desiderative Construction in Terms of Person/ Number in Samoan

\begin{tabular}{l|ll}
$1 \mathrm{SG}$ & $1 \mathrm{PL}$ & $3 \mathrm{rd}$ \\
$\mathrm{2SG}$ & $2 \mathrm{PL}$ &
\end{tabular}

For this phenomenon, Chung (1978: 128) states that "the motivation for such a restriction is not at all clear". Also, it is contrary to the universal tendency that for the third person "the need is greatest to keep track of reference" (Comrie 1983: 25). However, the motivation for the phenomenon might be partially explained as follows. According to Mithun (1994: 255), "absolutives share a crucial functional feature: they represent the participant that is the most immediately or directly involved in event or state". Absolutive here refers to $\mathrm{S}$ arguments and $\mathrm{P}$ (or $\mathrm{O}$ ) arguments (i.e., the least agent-like argument of a multi-argument clause). However, probably $\mathrm{S}$ arguments in intransitive clauses are more prominently involved in events or states than $\mathrm{P}$ arguments in transitive clauses in that they are the only arguments in the clause. And, in general, first and second person are more prominent than third person in that they are speech-act participants. For number variations, the singular occurs "much more frequently than the plural" (Corbett 2000: 282). Corbett claims that singular nouns are used in texts in several languages in more than 70 percent of cases. ${ }^{14}$ All in all, there could be some motivation for the first/second person singular in an S argument to be treated differently from the other combinations of person and number.

In addition, why equi-deletion is not applicable to clitic pronouns is probably that they are by nature weak in terms of indicating the prominence of the first and second person singular relative to

${ }^{14}$ In his data, Upper Sorbian shows somewhat lower frequency than the other languages. The singular in Upper Sorbian is found 64 percent of the time. 
independent pronouns. Duranti (1981: 137) mentions that clitic forms are "usually found in background, or apologetic statements", while independent forms are "in rather strong, emphatic declarations." That is, when the control is the first or second person singular clitic pronoun, there may be a motivation to present the prominence of the referent by overt marking of the clitic pronoun. However, even if the discussion might be plausible, it still fails to account for the question as to why the split is found solely in complements of 'want' (and 'go'). This should be investigated in the future.

\subsection{Kurmanji}

The split found in the Samoan desiderative construction is not an exceptional case. There is another language in which only the first person pronoun is overtly marked in intransitive desiderative complements (although grammatical number is not relevant to this case). In the spoken language of Kurmanji, intransitive complements of desiderative constructions usually take overt pronominal words of the $\mathrm{S}$ arguments which are coreferential with the subject of a matrix clause (or they take a subordinate marker):

$\begin{array}{lll}\text { Min } & \text { di-xwest } & \text { ez } \\ \text { I:OBL } & \text { PROG-wanted- } \varnothing & \text { I:NOM } \\ \text { her-im } & \text { mal-ê. } & \\ \text { go:SUBJN-1SG } & \text { home-OBL } & \end{array}$

'I wanted to go home.'

(Matras 1997: 627)

In (23), the predicate of the desiderative complement is an intransitive verb 'go', and it requires the overt pronominal $e z$ 'I:NOM' which is coreferential with the subject of 'want'.

However, the transitive complement of a desiderative construction usually does not contain an overt pronoun of the A argument (i.e., 
the most agent-like argument of a multi-argument clause) which is coreferential with the subject of the matrix clause, as in (24). (24) contains a transitive verb 'drink' as the predicate of the desiderative complement, but there is no overt pronoun for the A argument.

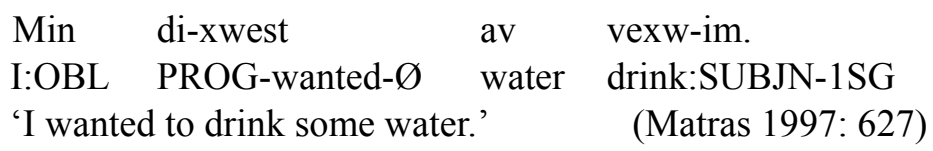

This distinction between intransitive predicates and transitive predicates is, however, found only when the subject of a desiderative complement is the first person. When the subject of a desiderative complement is the third person, the complement usually does not require an overt pronoun (or a subordinate marker) irrespective of transitive/intransitive of the predicate, as in (25).

\author{
a. Wî \\ he:OBL \\ mekîna-k-ê \\ car-INDEF-OBL \\ 'He wanted to buy a car.' \\ b. Wî \\ di-xwest \\ he:OBL PROG-wanted- $\varnothing$ \\ mal-ê. \\ home-OBL \\ 'He wanted to go home.'
}

di-xwest

PROG-wanted- $\varnothing$

bi-kirr-e.

SUBJN-buy-3SG

(Matras 1997: 629)

her-e

go:SUBJN-3SG

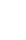

(Matras 1997: 629)

(25a) contains a transitive verb 'buy' as the complement of 'want' and (25b) an intransitive verb 'go', but both examples do not contain an overt pronoun as the A or S of their complements, respectively.

Again, in Kurmanji, it is solely the first person of the $\mathrm{S}$ argument of a desiderative complement that is marked overtly with the 
140 Desideratives and Person: Constructing a Semantic Map

pronoun (although there was no information on the distinctions between singular/plural or first/second person).

\section{3rd Person Pronoun vs. Others: Tagalog}

Another kind of split regarding desiderative construction is found in Tagalog. In Tagalog, the speaker's wish can be expressed with "optative" constructions in which "[the wished] action is to be performed by some person(s) other than the speaker and the person(s) addressed" (Schachter \& Otanes 1972: 407). ${ }^{15}$ In these constructions, the enclitic sana (or other enclitics) is obligatorily placed after the verb when "the actor is expressed by something other than a third-person pronoun" (ibid.: 408):

(26) Lexical Nouns and 1PL Exclusive (Schachter \& Otanes 1972:408)

a. Makita sana ni Maria ang singsing. to see SANA ART M. TOP ring 'I hope Maria finds the ring.'

b. Makita sana ng katulong ang singsing. to see SANA ART maid TOP ring 'I hope the maid finds the ring.'

c. Makita sana namin ang singsing. to see SANA 1PLe TOP ring 'I hope we (I and others) find the ring.'

a'. * Makita ni Maria ang singsing. to see ART M. TOP ring 'I hope Maria finds the ring.'

15 Since Schachter and Otanes use the term optative for the construction discussed in this section, I follow their terminology. 


b'. * Makita ng katulong ang singsing.
$\begin{aligned} & \text { to see } \\ & \text { 'I hope the maid finds the ring.' }\end{aligned}$
c'. * Makita namin ang
$\begin{aligned} & \text { to see } \\ & \text { 'I hope we (I and others) find the ring.' }\end{aligned}$

(27) Third Person Pronoun

a. Mangisda act.of.fishing

'I hope they go fishing.'

b. Mangisda sila. act.of.fishing 3PL

'I want them to go fishing.'
(Schachter \& Otanes 1972: 409) sila. 3PL

In (26), the actor of a wished action is either a lexical noun (Maria 'Maria' or katulong 'maid') or the first person plural exclusive pronoun (namin). In these cases, the enclitic sana obligatorily occurs after the verb makita 'to see'. The sentences, (26a) to (26c), in which the enclitic sana occurs, are grammatical, while (26a') to (26c') in which sana is omitted are ungrammatical. On the other hand, in (27) the third person plural pronoun sila is the actor of the wished action, and the occurrence of sana is optional.

The function of sana is to change "the meaning of the construction from the expression of a wish to the expression of a hope" (ibid.: 408). However, as the examples in (26) and (27) show, this change is possible only when the actor of the wished action is a third person pronoun. When the actor is not a third person pronoun, the only possible expression is the 'hope' version that contains sana.

An intriguing fact of the distribution of sana is that the first person plural exclusive pronoun (and also the first person plural inclusive, according to my language consultant) takes the same distributional pattern as lexical nouns. This distributional pattern can 
142 Desideratives and Person: Constructing a Semantic Map

be illustrated on an animacy hierarchy, as in (28). ${ }^{16}$

(28) Distribution of sana and the Animacy Hierarchy

1PLe/i $>3$ pronouns $>3$ full nouns

sana (obligatory) sana (optional) sana (obligatory)

However, this is an unexpected phenomenon in terms of an animacy hierarchy in which there should not be breaks in the range. A question then arises: Why is the first person plural pronoun treated in the same way as a lexical noun, and not as the third person pronoun? According to Givón (2001: 418, originally in Givón ed. 1983), "unstressed anaphoric pronouns are used in context of maximal referential continuity," so that "their co-referent... is found - overwhelmingly - in the immediately-preceding clause". He continues that this is a sharp contrast with (definite) full-NPs in that the coreferent of a full NP "is found much further away in the preceding discourse, often not even in the same clause-chain or paragraph" (Givón 2001: 419). Considering the distinction between third person pronouns and full nouns in terms of referentiality in discourse, it seems that the first and second person pronouns are rather closer to lexical nouns than to third person pronouns in that their referent is free from 'referential continuity', since they are basically deictic in nature (Siewierska 2004: 7). Third person pronouns are used in many cases to refer to a referent mentioned within two or three preceding clauses, while lexical nouns and first/second person pronouns are used without such a discoursal constraint.

However, even if the reason why third person pronouns are

16 The following is probably the most common representation found in the literature (Croft 2003: 130):

1st/2nd person pronouns $>$ 3rd person pronoun $>$ proper names $>$ human common noun $>$ nonhuman animate common noun $>$ inanimate common noun 
different from first person plural pronouns and lexical nouns can be explained in this way, it still remains unclear why the sana construction (or desiderative construction) is sensitive to the distinction.

Although this unresolved question is left to future research, it seems to be necessary to represent the distribution of sana in Tagalog in a way different from the animacy hierarchy in which it shows a break. To do so, it could be represented in a somewhat complicated diagram in which the first person plural pronouns are grouped together with lexical nouns. This is discussed in the following section.

\section{Conceptual Space for Desideratives}

In this section, I apply the semantic map model to capture the person splits found in the desiderative constructions in this study, and demonstrate how they are represented in the model.

Perhaps, an animacy hierarchy could serve as an underlying conceptual space for desideratives since the phenomena discussed in this paper have to do with person differences. In fact, in Croft (2003), the animacy hierarchy has been reinterpreted and represented under the concept of the semantic map model, and is represented as follows.

(29) Animacy Hierarchy in the Semantic Map Model

(Croft 2003: 134)

1st/2nd pron.-3rd pron.-Human N.-Animate N.Inanimate $\mathrm{N}$.

This diagram could be a conceptual space (or underlying diagram) for desideratives, on which we can draw semantic maps of 
each variation found in this study. However, it seems that this diagram cannot be applied simply for the phenomena found in desiderative constructions in this study. As discussed in previous sections, we need to take into account number distinctions and the case in which third person pronouns are differently treated from first/second person and third person lexical nouns. That is, we need to construct a somewhat different diagram for desideratives.

To construct a conceptual space, first we need to take into account the distinction between first/second person and third person. This distinction is found in several languages, such as Japanese, Korean, Hua, and Cocopa, in desideratives, as discussed in section 3. This should be represented in a conceptual space. In addition, second person should be separated from first person. This is because in Hua the form of second person desiderative differs from the form of the first person desiderative, as discussed in 3.3. Probably, second person is better placed in a different dimension from the dimension for the first and third person in a conceptual space, since second person is rather different from the first person and third person in that in various languages the desire of a second person cannot be expressed as a simple statement, but only as a question. Considering this, a conceptual space can tentatively be represented like the one as follows.

(30) Tentative Conceptual Space for Desideratives (1)

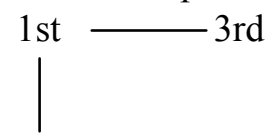

2nd

Given the tentative conceptual space for desideratives above, we can represent the patterns found in languages such as Japanese and Hua as in (31). 
(31) Semantic Maps for Desideratives

a. Japanese

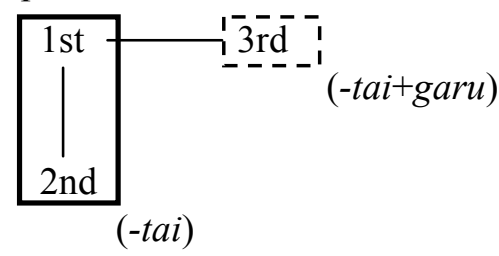

b. Hua

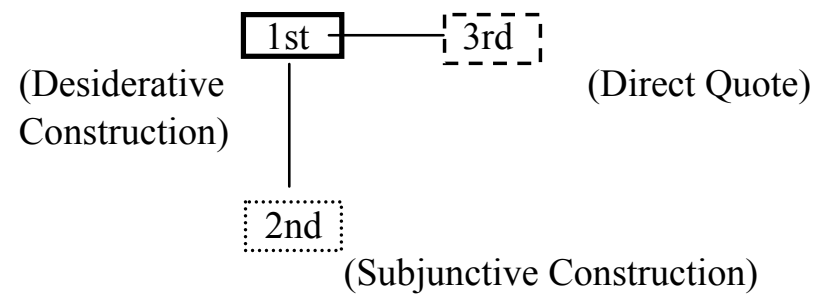

In Japanese, a first/second person's desire is expressed only by the desiderative suffix -tai following a verb stem, but the additional suffix -garu (or other elements such as sooda 'HEARSAY' or yooda 'seem') must follow the desiderative suffix when third person is the subject. This is represented as in (31a). Meanwhile, (31b) is for patterns found in Hua in which desideratives with the first person subject is expressed by desiderative construction, those with the second person subject is by subjunctive construction, and those with the third person subject is by direct quote construction.

Further, the distinction between first/second person singular and the other person/number combinations should be reflected in the conceptual space for desideratives. As discussed in 4.1, it was found in Samoan desiderative constructions that the first and second person singular clitic pronouns differ from the other person/number clitic pronouns in that only the first and second person singular clitic pronouns do not allow equi-deletion when they are coreferent with the $\mathrm{S}$ argument of the intransitive complement of desiderative 
constructions, while the other person/number clitic pronouns allow equi-deletion in the same context. This distinction should also be represented in the conceptual space diagram. A diagram taking the distinction into account can be drawn as follows.

(32) Tentative Conceptual Space for Desideratives (2)

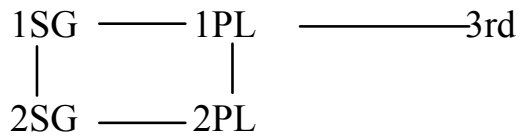

With this diagram, a semantic map regarding equi-deletion in Samoan desideratives can be represented as in (33).

(33) Semantic Map for Samoan Desideratives

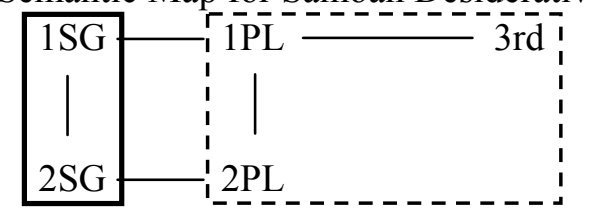

(Non-equi Deletion) (Equi-deletion)

In addition, considering the case of the Tagalog desiderative construction, third person pronouns are also placed in a different dimension in the space, not aligned directly between the first person and the third person lexical nouns. The following diagram (34) reflects the distinction found in Tagalog (and all the other distinctions found in the previous discussions). ${ }^{17}$

17 The first person plural exclusive is placed close to the third person pronoun and lexical noun, since it refers to a speaker himself and another third person referent(s). On the other hand, the first person plural inclusive is placed close to the second person pronoun, since it refers to a speaker and hearer(s). 
(34) A Conceptual Space for Desideratives ${ }^{18}$

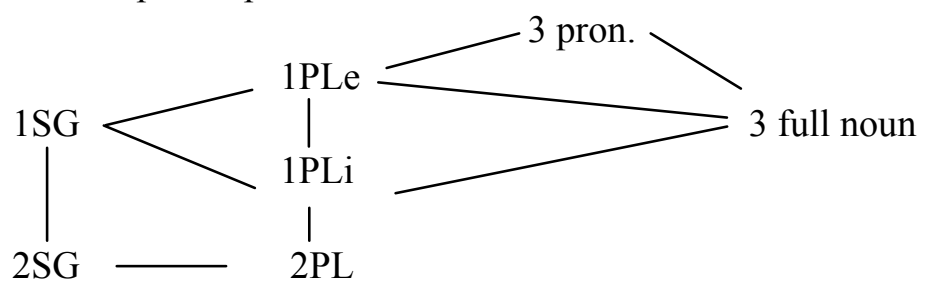

Given the conceptual space as above, we can represent the person splits found in desiderative constructions in Tagalog. As discussed in section five, regarding the distribution of sana in Tagalog, it is optionally used in expressions of desire when the wished action is performed by the referent of the third person pronouns, while it is obligatorily used when the referent is expressed with other than the third person pronouns. According to this distributional pattern, a semantic map for sana is represented as in (35).

(35) Semantic Map for sana in Tagalog ${ }^{19}$

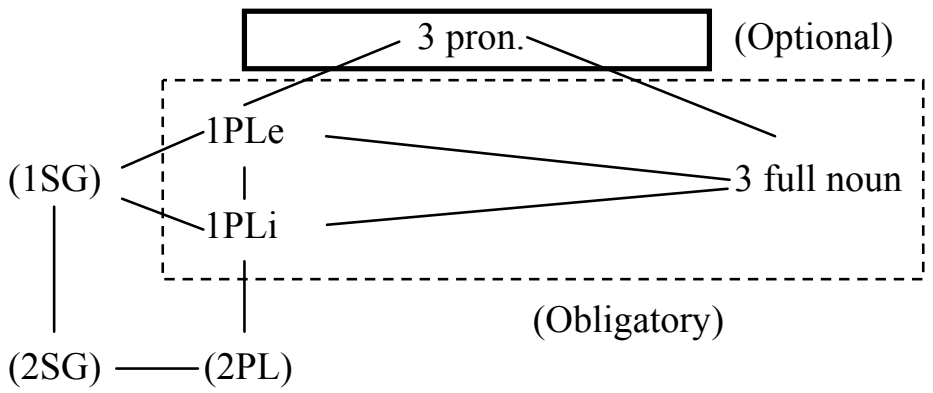

18 In the diagram, 2SG and1PLi (or 1PL) is not linked by a connecting line. This is because no examples have been found to link the two categories (i.e., treated in the same way) in desideratives.

19 Since the first person singular and the second person are irrelevant to sana construction, they are parenthesized. 
148 Desideratives and Person: Constructing a Semantic Map

The proposed conceptual space in (34), needless to say, can represent the other distinctions found in this study. For instance, in desideratives in Cocopa, a person split is found between first/second person and third person, as discussed in 3.4. This distinction is shown in conceptual space as in (36).

(36) Semantic Map for the Cocopa Desiderative

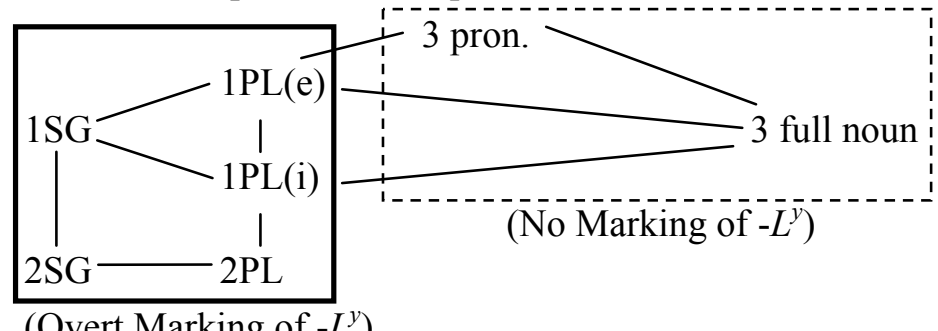

Also, although the distinction found in Hua was represented tentatively in (31b), this can be re-represented on the proposed conceptual space as in (37).

(37) Semantic Map for the Hua Desiderative

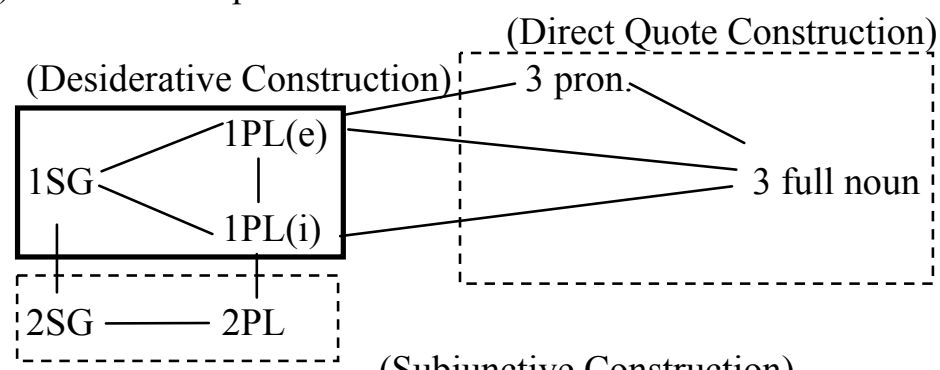

(Subjunctive Construction)

Lastly, for desideratives in Samoan, it was solely the first and second person singular clitics that do not allow equi-deletion while the other clitics allow it. This distinction can also be re-represented 
as in (38).

(38) Semantic Map for the Samoan Desiderative

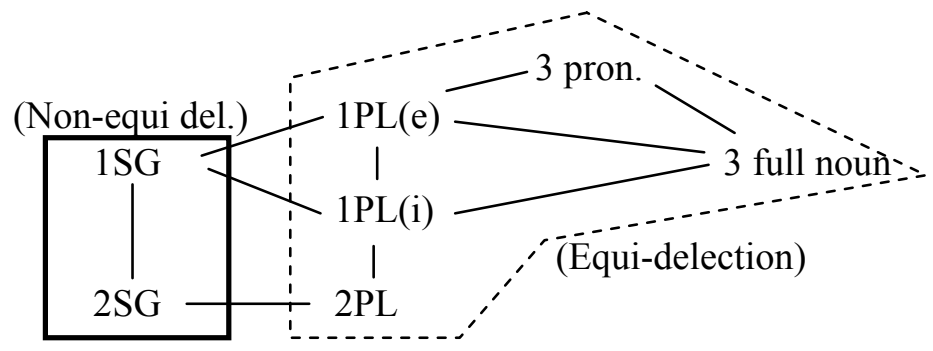

\section{Conclusion}

In this paper, I have discussed the implications of grammatical person for desiderative constructions from a cross-linguistic perspective. It was found that grammatical person does affect the form of desiderative constructions in several languages, and different marking patterns or constructions are employed according to person differences of the subject of 'want'. Person split between first/second person and third person was found in some languages such as Japanese, Korean, Hua, and Cocopa. Another type of person split was also found in desiderative constructions. In Samoan, only the first and second singular clitic pronouns are overtly indicated in the complement clause when they are coreferential with the subject of the matrix clause and are the S argument in the complement. In Kurmanji, it is the first person that is overtly indicated in the same context as the Samoan cases. Also, in Tagalog, the use of the enclitic sana is sensitive to person difference of the subject of the wished action. An intriguing phenomenon found in Tagalog is that first person plural pronouns take the same distributional pattern regarding sana as do lexical nouns, but third person pronouns do 
not. It is an unexpected phenomenon in terms of the animacy hierarchy, in which no breaks are expected in the hierarchy.

In order to capture the phenomena found in desiderative constructions in these languages, I adopt a semantic map model (e.g., Croft 2003) in the present study. Following the model and taking the phenomena discussed in this paper into account, the following conceptual space is proposed.

(39) Conceptual Space for Desideratives (Repeated from (34))

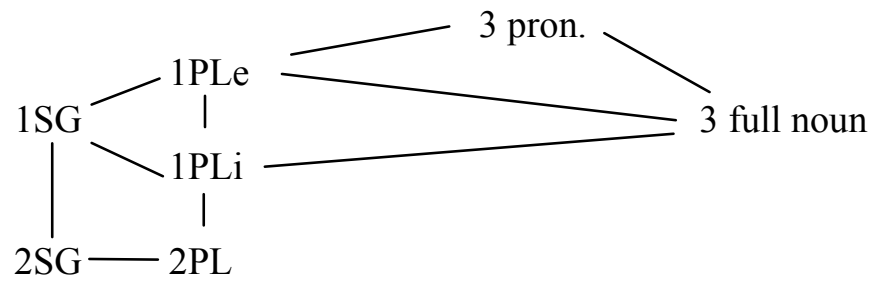

This underlying conceptual space for desideratives is constructed based on the phenomena found in desideratives in several languages. In the diagram, however, the distinction between singular and plural in third person is not indicated, since I have not encountered examples in which the form of desideratives differs between third person singular and plural. If there is a language that makes such a distinction in desiderative, this diagram could be modified. Also, since I have not obtained data in which some less frequent categories such as dual or trial affects the form of desiderative constructions in a language, such categories are not included. In this respect, this diagram is not conclusive and should be modified according to future study. 


\section{References}

Anderson, L. 1982. The 'Perfect' as a Universal and as a LanguageParticular Category. In P. Hopper (ed.), Tense-Aspect: Between Semantics and Pragmatics 227-64. Amsterdam: John Benjamins.

Aoki, H. 1986. Evidentials in Japanese. In W. Chafe \& J. Nichols (eds.), Evidentiality: The Linguistic Coding of Epistemology 223-38. Norwood, NJ: Ablex Publishing Corporation.

Chung, S. 1978. Case Marking and Grammatical Relations in Polynesian. Austin, TX \& London: University of Texas Press.

Comrie, B. 1983. Switch-Reference in Huichol: A Typological Study. In J. Haiman \& P. Munro (eds.), Switch-reference and Universal Grammar 17-37. Amsterdam: John Benjamins. . 1989. Language Universals and Linguistic Typology (2nd Edition). Chicago, IL: The University of Chicago Press.

Corbett, G. 2000. Number. Cambridge: Cambridge University Press.

Crawford, M. 1989. Cocopa Dictionary. Berkeley \& Los Angeles, CA: University of California Press.

Croft, W. 2001. Radical Construction Grammar: Syntactic Theory in Typological Perspective. Oxford: Oxford University Press. 2003. Typology and Universals (2nd Edition). Cambridge: Cambridge University Press.

Dixon, R. 1979. Ergativity. Language. 55, 59-138.

Duranti, A. 1981. The Samoan Fono: A Sociolinguistic Study. Canberra: Australian National University Press.

Givón, T. (ed.). 1983. Topic Continuity in Discourse: A Quantitative Cross-Language Study. Amsterdam \& Philadelphia: John Benjamins. . 2001. Syntax: An Introduction 1 (Revised Edition). Amsterdam \& Philadelphia: John Benjamins.

Gorbet, L. 1998. Subjectivity and Variation in Desiderative Constructions of Diegueño and Cocopa. In L. Hinton \& P. Munro (eds.), Studies in American Indian Languages: Description and Theory 10-15. Berkeley \& Los Angeles, CA: University of California Press.

Haiman, J. 1980. Hua: A Papuan Language of the Eastern Highlands of New Guinea. Amsterdam: John Benjamins.

Haspelmath, M. 1997. Indefinite Pronouns. Oxford: Oxford University Press. 
152 Desideratives and Person: Constructing a Semantic Map

. 2003. The Geometry of Grammatical Meaning: Semantic Maps and Cross-Linguistic Comparison. In M. Tomasello (ed.), The New Psychology of Language 2, 211-42. Mahwah, NJ: Lawrence Erlbaum Associates.

Im, H., G. Hong, \& S. Jang. 1989. Gaikokujin no Tame no Kankokugo Bunpou [A Korean Grammar for Foreigners]. Seoul: Yeonse Daehakgyo Chulpanbu.

Iwasaki, S. 2002. Japanese. Amsterdam \& Philadelphia, PA: John Benjamins. Kemmer, S. 1993. The Middle Voice. Amsterdam: John Benjamins.

Kuno, S. 1973. The Structure of the Japanese Language. Cambridge, MA: The MIT Press.

Martin, E. 1975. A Reference Grammar of Japanese. New Haven, CT \& London: Yale University Press.

. 1992. A Reference Grammar of Korean. Rutland, VT \& Tokyo: Charles E. Tuttle Company.

Matras, Y. 1997. Clause Combining, Ergativity, and Coreferent Deletion in Kurmanji. Studies in Language 21, 613-53.

Mithun, M. 1994. The Implications of Ergativity for a Philippine Voice System. In B. Fox \& P. Hopper (eds.), Voice, Form, and Function 247-277. Amsterdam: John Benjamins.

Mosel, U. \& E. Hovdhaugen. 1992. Samoan Reference Grammar. Oslo: Scandinavian University Press.

Nihongokyoikugakkai (ed.). 1982. Nihongokyoikujiten [A Dictionary of Teaching Japanese as a Foreign Language]. Tokyo: Taishukan.

Noonan, M. 1985. Complementation. In T. Shopen (ed.), Language Typology and Syntactic Description II: Complex Constructions 42-140. Cambridge: Cambridge University Press.

Schachter, P. \& F. Otanes. 1972. Tagalog Reference Grammar. Berkeley \& Los Angeles, CA: University of California Press.

Siewierska, A. 2004. Person. Cambridge: Cambridge University Press.

Silverstein, M. 1976. Hierarchy of Features and Ergativity. In R. Dixon (ed.), Grammatical Categories in Australian Languages 112-171. Canberra: Australian Institute of Aboriginal Studies.

Data sources (Korean)

The 21st Century Sejong Project Corpus (abbreviated as SPC in this paper)

The corpus itself is the creation of the National Academy of the Korean Language. However, the data referred to in this study is a part of the 
corpus (containing 5.5 million words collected in 1999, 2000 and 2001) that is available through the Internet with a concordancer called CETConc provided by Korea University. 